\title{
DIAZEPAM IN CARDIOVERSION*
}

\author{
LoRne N. VINGE, B.A., M.D., GoRdon M. WYANT, CD, F.F.A.R.C.S., F.R.C.P.(c), \\ AND JosE F. LOPEZ, M.D. $†$
}

ELECTRIC SHOCK BY THE direct current cardioverter is now the most rapid and the most consistently effective method of restoring sinus rhythm. It was first used and popularized by Lown and his co-workers ${ }^{1,2}$ in 1960 after initial studies with alternating current defibrillation were shown to cause increased frequency of ventricular fibrillation and were suspected of causing an increased incidence of post-shock acute myocardial infarction. In the early stages, some cardiologists did not use obtunding agents for this procedure, but the majority preferred and still prefer some type of general anaesthesia to obviate the pain associated with cardioversion. Nutter and Massumi ${ }^{3}$ were the first to report the use of intravenous diazepam as the sole agent for cardioversion. Muenster et al. ${ }^{4}$ compared thiopental in eighteen cardioversions with nineteen cases of intravenous diazepam. They initiated their study because they had been disturbed by the high incidence of premature ventricular contractions after intravenous thiopental, both before and after cardioversion. In their small diazepam series there were no such pvCs after diazepam and before cardioversion and also fewer pvcs after cardioversion; they seemed to credit the drug's supposed inherent antiarrhythmic properties for this.

Our first direct current defibrillation was done in October of 1963. This patient received an anaesthetic which included premedication with atropine, induction with thiopental, followed by succinylcholine for intubation, and maintenance with nitrous oxide-oxygen and halothane. This first cardioversion was unsuccessful. After a variety of techniques had been employed for some three and a half years, we began to use diazepam in March of 1967 and have done so as our agent of choice for cardioversions since that time. This study then must be regarded as a retrospective one relative to the pre-diazepam management of cardioversion, but is prospective thereafter. Hence a certain heterogeneity in our cases.

\section{Material}

This report encompasses a total of 161 cardioversions, 76 done with diazepam alone, the other 85 under a variety of other anaesthetics or a combination of anaesthetic agents. One hundred and twelve patients are involved, twenty having had two cardioversions, eight patients with three procedures, three patients had

\footnotetext{
"Presented at the Annual Meeting of the Canadian Anaesthetists' Society, Winnipeg, 23 June 1970.

tFrom the Departments of Anaesthesia and Medicine, University of Saskatchewan and University Hospital, Saskatoon, Saskatchewan.
} 
four procedures and one patient had five different shocks. One or more shocks were administered as required, and when more than one shock was administered, the usual initial energy was 100 watt seconds, subsequent shocks usually being of increasing increments of 100 watt seconds. The physical status of these patients is listed in Table I.

TABLE I

\begin{tabular}{crr}
\hline \hline Status & \multicolumn{2}{c}{ Number } \\
\hline I & Nil & \\
II & 10 & 11 \\
II E & $1\}$ & \\
III & 116 & 141 \\
III E & 25 & \\
IVE & 9 & 9 \\
\hline
\end{tabular}

Cardioversions were done at various locations in the hospital. These included primarily the Cardiopulmonary Laboratory, the Operating Room, and the Medical Intensive Care Unit, but other locations were used as well. The only essential prerequisites for cardioversion was that cardiovascular resuscitative equipment was immediately at hand and workable.

The underlying diseases are listed in Table II, the kinds of arrhythmias in Table III, and the age of patients submitted to cardioversion in Table IV.

Before induction all patients were monitored electrocardiographically to confirm that the arrhythmia was still present and to observe and record immediately any post-induction and post-shock arrhythmia.

The original group of patients were premedicated with a variety of agents, such as atropine alone and combinations which included pentobarbital and promethazine. Some of these patients were then given thiopental only, while others received in addition one or more of nitrous oxide, azeotrope halothane/ether, or halothane.

The diazepam group was premedicated with oral or intramuscular diazepam, the average dose being $10 \mathrm{mgms}$ given 1 to 2 hours before cardioversion. Induction consisted of 10 to $30 \mathrm{mgms}$ of diazepam, as required, into a large vein whenever possible. Although some anaesthetists prefer to use the "no pain response to a pinch" as their end point for induction, others like ourselves prefer merely to wait two or three minutes or until the patient's consciousness was obtunded before allowing the cardiologist to administer the shock. In some instances a second injection of diazepam was needed and occasionally a third one as well. In this respect it was noted that one could not predict always on a weight basis the exact amount of diazepam required to obtund consciousness, although this had been the original intention. Other authors have found this to be the case as well. ${ }^{5}$

\section{RFsults}

In the diazepam group 47 out of the 76 were converted to sinus rhythm with the first shock, the majority on 100 watt seconds. This amounts to an initial suc- 
TABLE II

Dise ASES

\begin{tabular}{lr}
\hline Thyrotoxicosis & 1 \\
Shock & 1 \\
Trauma & 1 \\
Wolfe-Parkinson-White & 2 \\
Uraemia & 6 \\
Cardiomyopathy & 1 \\
Myocarditis & 2 \\
Congenital heart disease & 3 \\
Myocardial infarction & 10 \\
A.S.H.D. & 12 \\
Idiopathic & 14 \\
R.H.D. & $\underline{108}$ \\
& \\
\hline
\end{tabular}

TABLE III

ARRHYThMiAS

\begin{tabular}{lr}
\hline Atrial fibrillation & 131 \\
Atrial flutter & 17 \\
Supraventricular or & 12 \\
ventricular tachycardia & 1 \\
Nodal tachycardia & \\
\hline
\end{tabular}

TABLE IV

\begin{tabular}{cr}
\hline \hline Ages & Number \\
\hline $10-19$ & 3 \\
$20-29$ & 3 \\
$30-39$ & 15 \\
$40-49$ & 37 \\
$50-59$ & 34 \\
$60-69$ & 12 \\
$70-79$ & 7 \\
$80-89$ & 1 \\
& 112 \\
\hline
\end{tabular}

cess rate of 62 per cent. It should be noted, however, that more recently the cardiologists have been using 200 watt seconds as their initial energy which seemed somewhat to increase the first shock success rate. Twelve patients were converted with two shocks, four required three and in one instance four shocks were given before cardioversion occurred. In no case was more than 400 watt seconds used. Overall, in the diazepam group 63 out of 76 , or 83 per cent were successfully converted, at least temporarily.

In the other group 29 out of 85 were corrected with one shock, representing a success rate of 34 per cent. Fourteen others were converted with two shocks, twelve with three, two with four, and one with five. The total cardioversion success rate in this group is 65 out of the 85 or about 76 per cent. If one takes the highest mean energy required for successful cardioversion, one finds that it required 178 watt seconds to convert successfully each one of the diazepam group and 183 watt seconds to convert each of the other group. 


\section{Discussion}

At first sight it would appear that the success rate after first shock cardioversion is convincingly higher after diazepam than after other anaesthetics. This relationship becomes less clear however when one compares the immediate success after whatever number of shocks was required to achieve cardioversion in each group and also when average shock energics are considered. The picture becomes even further confused by the fact that some patients who were not successfully converted with three shocks, had energies of 100 watt seconds each time, and the fact that some cardiologists now use an initial energy of 200 watt seconds.

There are of course many well known reasons for failure of cardioversion. Certainly the plethora of depressant agents used in anaesthetizing these patients in the early days of cardioversion would not be conducive to success. Other explanations for failures include the chronicity of fibrillation, predominance of mitral insufficiency, elevated left atrial pressure, increased left atrial size, hypokalaemia, hypoxia, digitalis excess, ctc. Some authors suggest that if cardioversion is unsuccessful, that there must be an abnomality in one of these parameters which if uncovered and corrected will result in subsequent successful cardioversion. ${ }^{6}$ On the other hand it is the feeling of many that the conversion rate is much lower and the remission rate higher in rheumatic heart disease than in other forms of heart disease. This may explain our results since we deal with a large proportion of patients with rheumatic heart disease.

It is inherently difficult to document the exact length of time these patients remain in sinus rhythm. It is well known that many relapses occur even within minutes or hours and that many more revert as time goes on. Most of our patients were followed as outpatients every three months by their cardiologist and our results would tend to bear out what others have found, namely that often no more than one-third are in sinus rhythm at six months. ${ }^{\top}$ Almost all of our patients from both groups were on digitalis and on an antiarrhythmic drug which usually was quinidine at the time of cardioversion. Patients were left usually on these drugs indefinitely unless there happened to be a particular contraindication to their use. Some of course forgot to take their quinidine or discontinued it on their own either because of side-effects or because they felt it was no longer needed. In our series only very rarely was digitalis omitted for the 48 hours or so suggested by some and this failure to discontinue the digitalis pre-cardioversion had no obvious deleterious effects on the procedure or on the post-shock cardiac rhythm.

Sixteen of the 62 successfully converted cases in the diazepam group showed some abnormality of cardiac rhythm immediately after cardioversion. This gives an arrhythmia rate of 25.8 per cent. These abnormalities in rhythm varied from one or two premature atrial or ventrical contractions to short episodes of ventricular tachycardia. On the other hand, 21 out of 64 (32.8 per cent) showed some post-shock arrhythmia in the other successfully converted group. At no time did these arrhythmias present a problem however, and without exception reverted spontaneously to sinus rhythm. In the majority of cases no attempt was made to 
synchronize the shock so as to avoid the vulnerable phase of cardiac excitation this presented no problems.

When one analyzes the patients who had more than one procedure, one of which was done with diazepam and the other in which some other agent was used, the results were equivocal. Some were successfully converted with a specific energy using diazepam, the procedure being unsuccessful with the same energy using for example thiopental, while others were successfully converted with a general anaesthetic and not converted with diazepam.

Friedburg ${ }^{8}$ in his textbook states that the only disadvantage of direct current shock is the present need for brief anaesthesia. Diazepam would thus seem to come as close as any to obviating the need of an attending anaesthetist. But since "any fool can press a button," the need for the presence of a trained physician, cardiologist, or anaesthetist, is certainly not negated. Diazepam causes no troublesome cardiovascular or respiratory depression, it acts almost as quickly and wears off nearly as fast as most agents. Patient acceptance is excellent, perhaps because of the very high incidence of amnesia. Side-effects were almost non-existent when injection was done into a large vein. Some patients do cry out momentarily at the time of the shock and some will sit almost bolt-upright on their stretchers if an inadequate dosage of diazepam has been given. An occasional patient had hiccoughs but this proved to be no problem. Cardiologist acceptance was initially less enthusiastic, perhaps because of their reluctance to electrocute patients whose eyes were still open. However, they too were converted quickly to this method. Even though diazepam had no unequivocal bearing on the success rate or the elimination of post-shock arrhythmias in cardioversion, its use certainly converts it into a relatively simple procedure. Diazepam therefore remains our hypnotic agent of choice in direct current defibrillation.

\section{RÉSUMÉ}

Ce travail décrit nos expériences au cours de 161 cardioversions par courant direct, dont 76 ont été pratiquées sous anesthésie au diazépam seul et 85 sous anesthésie par divers agents. Généralement le premier choc était de 100 watts seconde, et les suivants, si besoin, allaient en s'accroissant à partir de 100 watts seconde.

Dans le groupe du diazépam, 62 pour cent des versions ont été réussies au premier choc, alors que seulement 34 pour cent ont été réussies au premier choc sous anesthésie générale plus conventionnelle. Cependant, plus récemment, le premier choc a été souvent de 200 watts seconde, et comme tous les cas récents ont été pratiqués sous diazépam, nos résultats nous font pencher en faveur de la série au diazépam. Le taux global de cardioversion, quelque soit le nombre de chocs requis pour l'obtenir a été de 83 pour cent avec le diazépam comparé à 76 pour cent pour les cas d'anesthésie générale. La plus haute énergie moyenne requise pour réussir la cardioversion a été de 178 watts seconde pour le groupe au diazépam et 183 watts seconde pour les autres.

Bien que cette étude ne démontre pas un avantage énorme en faveur du diazépam par rapport aux autres formes d'anesthésie en autant que le pourcentage 
total de cardioversions réussies est concerné, l'usage du diazépam rend cette intervention beaucoup moins compliquée au point de vue du soulagement apporté à la douleur et au malaise qui accompagnent l'administration du choc électrique.

\section{REFERENCES}

1. Lown, Bernard; Amarasingham, Ragmavan; \& Neuman, Jose. New method for terminating cardiac arrhythmias; Use of synchronized capacitor discharge. J.A.M.A. 182: 548-555 (1962).

2. Lown, Bervard; Neuman, Jose; Amarasingham, Raghavan; \& Berkovits, Barough V. Comparison of alternating current with direct current countershock across the closed chest. Am. J. Cardiol. 10: 223-233 (1962).

3. Nutter, D. O. \& Massumi, R. A. Diazepam in cardioversion. New England Journal of Medicine. 273: 650-651 (1965).

4. Muenster, Joseph J.; Rosenberg, Marvin S.; Carleton, Richard A.; \& Graettinger, JoHN S. Comparison between diazepam and sodium thiopental during D.C. countershock. J.A.M.A. 199: 758-760 (1967).

5. Brown, S. Stuart \& Dundee, John W. Clinical studies of induction agents xxy: Diazepam. Brit. J. Anaesth. 40:108-112 (1968).

6. Wagner, Galen S. \& McIntosh, Henry D. The use of drugs in achieving successful D.C. cardioversion. Progress in Cardiovascular Diseases 11: 431-442 (1969).

7. Selzer, Arthur; Kelly, John J., Jr.; Johnson, Roger B.; \& Kerth, William J. Immediate and long-term results of electrical conversion of arrhythmias. Progress in Cardiovascular Diseases 9: 90-104 (1966).

8. Friedberg, Charles K. Diseases of the Heart, 3rd Edition, W. B. Saunders Company, Philadelphia and London. 